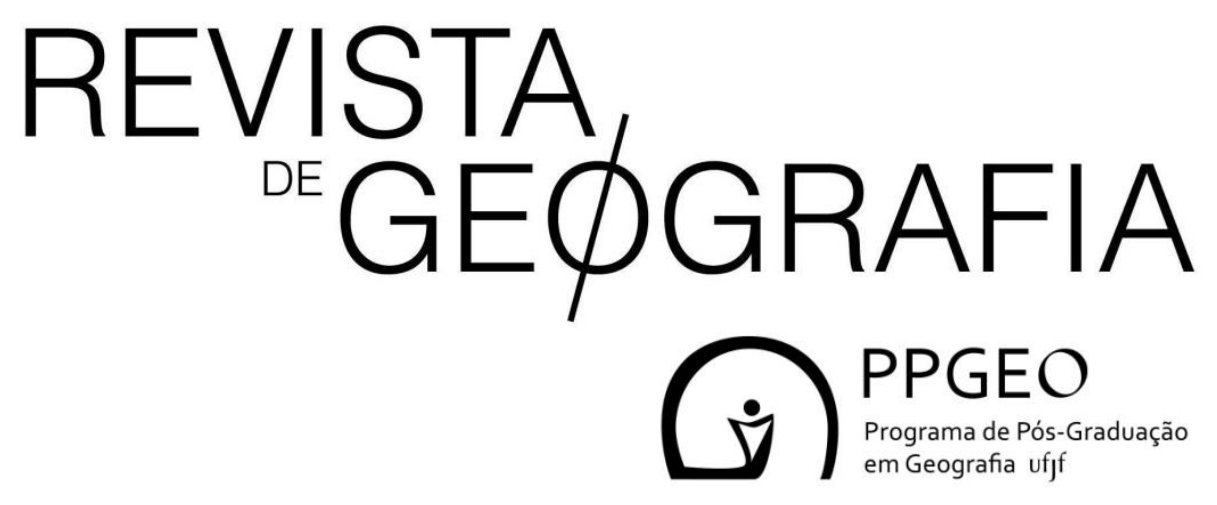

\title{
À SOMBRA DO CAPITAL, CORPOS DESCARTÁVEIS E A EXCLUSÃO DAS POPULAÇÕES PERIFÉRICAS FRENTE À COVID- 19 EM BELO HORIZONTE - MG
}

IN THE SHADOW OF THE CAPITAL, DISPOSABLE BODIES AND THE EXCLUSION OF PERIPHERAL POPULATIONS IN FRONT OF COVID-19 IN BELO HORIZONTE - MG

Carolina Maria Soares Lima Universidade Federal de Minas Gerais Av. Pres. Antônio Carlos, 6627 - Pampulha,

Belo Horizonte - MG, 31270-901

E-mail:carolmsoares98@gmail.com

Jackson Junio Paulino de Morais Universidade Federal de Minas Gerais Av. Pres. Antônio Carlos, 6627 - Pampulha, Belo Horizonte - MG, 31270-901 E-mail:jacksmorais@hotmail.com 


\section{Resumo}

Este trabalho buscou analisar e apresentar discussões à luz da COVID-19, relacionando as periferias urbanas e os corpos que nelas habitam. Para subsidiar a argumentação ao longo do texto foram utilizados conceitos como: Eugenia, Neomalthusianismo, Risco e Vulnerabilidade. Além disso, buscou-se realizar retomada histórica sobre a crise urbana para elucidar as noções do direito à cidade no cenário contemporâneo. Por fim, foram analisados e justapostos dados e mapas sobre o contágio e óbitos pela COVID-19 em Belo Horizonte, localizada em Minas Gerais, corroborando com a ideia de que os impactos causados pela dispersão e contaminação do novo Coronavírus se dá de forma desigual pelo espaço urbano.

Palavras-chave: Covid-19; Periferias, Risco; Vulnerabilidade; Belo Horizonte.

\section{Abstract}

This study sought to analyze and present discussions in the light of COVID-19, relating the urban peripheries and the bodies that inhabit them. To support the argument throughout the text, concepts such as: Eugenia, Neomalthusianism, Risk and Vulnerability were used. In addition to a historical return to the urban crisis to elucidate the notions of the right to the city in the contemporary scenario. Finally, data and maps on contagion and deaths were analyzed and juxtaposed by COVID-19 in Belo Horizonte, located in Minas Gerais, corroborating the idea that the impacts caused by the dispersion and contamination of the new Coronavirus occur unevenly through urban space.

Keywords: Covid-19; Peripheries, Risk; Vulnerability; Belo Horizonte.

\section{Introdução}

O presente trabalho, analisa e apresenta discussões sobre as relações da COVID19 com as periferias urbanas e os corpos que nela habitam. Para subsidiar a argumentação aqui disposta utilizamos conceitos da Ecologia Política, produzindo uma retomada histórica da crise urbana, além de trazer à luz as noções de direito à cidade, risco e vulnerabilidade no cenário contemporâneo. Além disso, discursos e práticas governamentais são interpretados e justapostos a dados e mapas sobre a dispersão da COVID-19 em metrópoles brasileiras, em especial em Belo Horizonte - MG, considerando a volta do discurso neomalthusiano/eugenista.

Tal interpretação se dará através da análise crítica da narrativa (MOTTA, 2013), metodologia que lança mão de análises de narrativas como fato cultural, para possibilitar a compreensão das relações com os jogos de poder circundados, as estratégias, hierarquias, possibilidades e limites que permeiam as negociações do discurso.

Através da contraposição de conceitos já elaborados previamente, desde o século passado, ou antes, com conceitos e noções propostos por diversos estudiosos frente ao cenário da crise sanitária presente, buscamos ilustrar a forma como corpos à sombra do capital são abandonados e descartados pelo Estado e pelo capital. Esse abandono não

ISSN: 2236-837X 
acontece apenas na metrópole, ainda que seja o foco deste trabalho, e não apenas durante a pandemia. Os atores de base, as periferias globais, urbanas e os povos subalternizados são abandonados desde o advento da modernidade. A pobreza sempre foi demonizada (ESCOBAR, 1996). As relações de poder que a atravessam são frequentemente desconsideradas, de forma que os pobres sempre foram responsabilizados por seus insucessos, dirimindo a responsabilidade do Estado.

$\mathrm{Na}$ primeira parte deste trabalho, construímos uma base teórica sobre égide da Ecologia Política, refletindo sobre o urbano, suas especificidades à luz do neomalthusianismo e concepções eugenistas. Na segunda parte, lançamos mão dos conceitos de risco e vulnerabilidade para refletir sobre o atual contexto pandêmico, além de ilustrá-lo com dados e falas que corroboram com um abismo quase definitivo entre estes sujeitos que ocupam o espaço urbano. Na terceira e última parte, trabalhamos com a escala do fenômeno em Belo Horizonte - MG, expondo a maneira desigual com que as consequência da dispersão da COVID-19 atingem os espaços e os corpos que nele habitam.

É importante salientar que esta pesquisa foi desenvolvida ao longo de 2020, em meio à crise do novo Coronavírus, o que resultou em uma experiência de construção lado a lado do objeto de estudo. Para sermos mais precisos, este trabalho foi produzido no primeiro semestre de 2020, o que justifica possíveis ausências dos atuais contextos e desdobramentos no campo pesquisado.

\section{Corpos descartáveis à sombra do capital}

Malthus (1798) postula, em seu ensaio sobre a população, que os alimentos (ou recursos) seriam necessários para a existência humana e que o desejo sexual sempre estaria presente. A partir disso, a capacidade do crescimento da população seria maior que a capacidade da Terra de produzir tendo, no horizonte do desenvolvimento, a pobreza inevitável e culpada por suas próprias mazelas. As políticas baseadas no malthusianismo não foram esquecidas, ainda que as teorias tenham sido fortemente refutadas e que os objetivos do desenvolvimento econômico e os da conservação não são conflitantes já é conhecido.

O discurso neomalthusiano é fundado no neoliberalismo, uma vez que o "nãodesenvolvimento" dos países em desenvolvimento é essencial para sustentar a política dos países desenvolvidos. Na atualidade, graças à globalização e a compreensões ligadas ao desenvolvimento, não se utiliza dos termos como países de terceiro ou primeiro mundo: concebemos os conceitos de periferias (dinâmicas e deprimidas) e centros do capitalismo,

ISSN: 2236-837X 
que podem ser conceitos chaves para compreender as dinâmicas globais, nacionais, regionais e até mesmo intra-urbanas. Nas ciências biológicas, o termo "eugenia", cunhado por Galton (1883), se refere ao conjunto de práticas consistentes no desestímulo da reprodução das classes populares e no estímulo da reprodução das elites, devido à necessidade de prosperar as linhagens melhores e mais puras, acreditando que alguns seres humanos seriam mais aptos e melhores para a manutenção da vida no planeta. $O$ malthusianismo e o neomalthusianismo são como o espelho da eugenia dentro das humanidades, ao postular que as classes mais baixas são mais indignas da reprodução, por serem causadoras dos mal-estares sociais.

As ideias malthusianas e eugenistas que, no imaginário coletivo, são ideais retrógrados, retomam fortemente sua presença na agenda política de forma repaginada, quando observamos que as classes mais populares são expostas mais fortemente ao risco e à vulnerabilidade, tanto, na prática, quanto no discurso, como se seus corpos fossem descartáveis. Achille Mbembe em seu livro "Crítica da Razão Negra" explora a noção de devir-negro do mundo e, num momento passado, no momento de espoliação, no qual homens e mulheres negros e negras eram transformados em moeda e mercadoria pelos brancos europeus e, mais recentemente, no neoliberalismo, a vida social passa a ser codificada em normas de mercado. A multidão faz-se entregue ao abandono e o tratamento que o negro recebia desde o momento da espoliação, em especial as classes mais baixas da sociedade (MBEMBE, 2017).

Segundo Mbembe (2003), a capacidade de determinar, dentro de um território, quem pode viver e quem pode morrer, é a expressão máxima da soberania dos Estados. Isso ocorre porque o Estado controlaria o que o autor chama de "funções assassinas" e faz aceitável o "fazer morrer", pois se faz possível determinar quem é descartável. Isso é observado através de práticas políticas visíveis de violência, física ou simbólica. Quando ancoradas em ideais eugenistas ou malthusianos, as práticas da necropolítica são mais facilmente exequíveis, pois, ao transferir aos pobres a responsabilidade sobre sua resiliência, exime do Estado a obrigação de assegurar serviços básicos para a manutenção da vida.

Sachs (2000) destaca que o desenvolvimento não é fundado apenas no crescimento e que deve considerar a distribuição, participação e desenvolvimento humano. O mesmo autor aponta ainda que o crescimento não é suficiente para mitigar a pobreza se cegado pelas relações desiguais de poder. A lógica neoliberal que tange a produção do espaço urbano é essencialmente competidor e segregador, além de responsabilizar cada indivíduo por seus sucessos e fracassos - e impor que estes tenham implicações nos sucessos e fracassos da coletividade. Escobar (1996) aponta para problemáticas do campo da ecologia

ISSN: 2236-837X 
política tais como 1) assumir que todos os problemas são iguais globalmente e 2) a demonização da pobreza. Tais problemas eram apontados pelo autor no final do século passado, mas não devem ser deixados a par das construções das análises no campo sob uma perspectiva crítica.

\section{Risco e vulnerabilidade em tempos de COVID-19}

As crises geradas e elucidadas pela COVID-19 (sanitária, política e urbana), trazem a pauta da vulnerabilidade para o nível global e, apoiada em noções de risco, a análise dessa crise elucida que os riscos são apresentados aos extratos sociais de maneira diferente. Contudo, a noção de risco já era previamente observada em sentidos distintos para tais extratos e isso mostra-se explicável pelas bases neoliberais as quais o Estado brasileiro se funda. Na metrópole fica mais evidente, simultaneamente, a vulnerabilidade e a segregação, além da desigualdade social, pois há pequenas casas com muitas pessoas, pouca água e mesas sem comida e isso é fonte do processo fundantes da cidade na modernidade.

A principal forma de combate e prevenção ao novo Coronavírus, além do auto isolamento, consiste em lavar as mãos com água e sabão. Lavar as mãos nos torna mais protegidos, no entanto, nem todos têm acesso a sabão e nem a água (UNICEF, 2020). A água deveria ser um recurso comum, ou seja, um recurso que pertence a todos igualmente e não como ocorre, um recurso cujo acesso é limitado a grupos historicamente marginalizados. A distribuição e a limpeza da água a partir do Estado é mais eficaz do que quando ocorre a partir do mercado, pois o Estado opera com valores e tarifas mais baixas, enquanto o mercado realiza cobranças mais competitivas e, consequentemente, excludentes. No Brasil, um quarto da população não tem água chegando em suas casas (MORADO, 2020), ou seja, mais de 30 milhões de brasileiros não podem se proteger adequadamente da COVID-19 por falta de água.

De acordo com a Comissão Mundial de Meio Ambiente e Desenvolvimento - WCED (1987), cada vez mais pessoas vivem com falta desse recurso. Quando alguém se apropria de um recurso natural, impossibilitando o uso de outra pessoa, em especial no caso da água, esse sujeito transforma o insumo básico da vida de outras pessoas em lucro (DARDOT, LAVAL, 2017). A água deveria ser considerada um comum urbano -e não apenas urbano - e tratada com o caráter comum, com uso difundido entre todos, contudo, essa não é a realidade das periferias na metrópole. O que podemos ver agora é que, graças a uma doença devastadora, a falta de água está tirando mais vidas do que antes e a grande mídia começou a dedicar-se a denunciar tal fato. Os grupos que são mais afetados

ISSN: 2236-837X 
pela falta de água e saneamento básico são os historicamente marginalizados nas metrópoles brasileiras.

Em geral, o comum é o conjunto de bens e recursos coletivamente compartilhados, usados e geridos por uma comunidade. A ideia do comum urbano é essencialmente marcada no imaginário político das lutas urbanas e ajuda a pensar a reforma urbana. $\mathrm{A}$ noção dos comuns surge a partir da compreensão do que vem a ser os cercamentos e, na cidade, os territórios que não são requeridos pelo capital são tidos como territórios à margem, excluídos ou sobrantes da urbanização formal, sendo uma patologia a ser eliminada (TONUCCI \& COSTA, 2017). Os grupos periféricos, desde antes da crise do novo Coronavírus, já eram tidos como alvo de políticas higienistas: a partir da COVID-19, eliminar as "patologias urbanas" fica mais fácil através de práticas de abandono dessas populações e seus territórios a partir do gerenciamento governamental.

Gonçalves (1995) aponta que a questão urbana, no final do século passado, seria o principal problema socioambiental do país, uma vez que reflete as consequências perversas do modelo de desenvolvimento. O autor destaca que o fato do Estado não investir adequadamente em infraestrutura social e saneamento urbano resulta em um processo de favelização, gerando um alto 'déficit' habitacional. Devido ao conjunto de fatores impulsionados por esse 'déficit' e outras questões urbanas, os mais pobres erguem suas habitações em encostas instáveis, próximas a depósitos de lixo em geral, em ambientes vulneráveis.

De acordo com Monte-Mór (1994), o acesso ao solo urbano fortalece o sentido do valor de uso, colocando as populações pobres na economia popular urbana, identificada por ambulantes, agricultores urbanos, artesãos, entre outras ocupações que utilizam do espaço urbano. Ainda segundo o autor, a urbanização brasileira é fortemente marcada por uma economia de crescente exclusão, que extrai todo e qualquer excedente passível de acumulação dos sujeitos subalternizados.

A dispersão da COVID-19, de acordo com Diniz et. al. (2020) gera vários efeitos imediatos sobre a economia popular urbana, pois elas dependem essencialmente do uso do território e tais efeitos também geram impacto direto sobre a população de rua, que frequentemente depende de doações daqueles que circulam pelas cidades. Percebe-se que a crise atual, coloca luz sobre processos e outras crises que já eram verificadas, pelo menos desde o final do último milênio, e agrava a situação de risco e vulnerabilidade para populações que já eram extremamente afetadas pelas crises urbanas.

Como já explicitado, a pandemia da COVID-19 nos mostra a vulnerabilidade em sentido global. Alguns países apresentam medidas de mitigação da contaminação do vírus, além de uma rede de proteção que diminui os danos sociais e econômicos. Porém, no caso

ISSN: 2236-837X 
do Brasil, a pandemia é enfrentada a partir do risco e da vulnerabilidade desmedidos e na ausência do poder público em âmbito federal, principalmente no que tange os moradores das periferias e favelas.

De acordo com Castro et al. (2005), o risco está relacionado às noções de incerteza, exposição ao perigo, perda ou prejuízos materiais, econômicos e sociais. Já a vulnerabilidade, está associada à maneira diferenciada em que a sociedade é impactada pelos riscos. Dessa forma, a vulnerabilidade está diretamente relacionada a dois aspectos: o modo de ocupação do território, normalmente seguindo o padrão em que, as classes mais pobres ocupam áreas ambientalmente mais suscetíveis; e também com as especificidades de diversos subgrupos na sua vida diária (VALENCIO et al., 2006). A vulnerabilidade urbana, que se atrela a contingentes sociais, políticos e econômicos, por exemplo, evidenciam a heterogeneidade dos impactos do risco sobre a população, que passa a estar numa situação de risco e vulnerabilidade simultaneamente (MENDONÇA, 2011).

A sociedade de riscos apontada por Beck (2011), se faz extremamente atual em tempos de pandemia do novo Coronavírus, pois, se considerarmos os pressupostos essenciais de sua obra que caracterizam a sociedade de riscos, observamos a direta relação com a realidade pandêmica vivenciada. Diante disso, considerando características como adensamento populacional, condições precárias de infraestrutura sanitária, habitacional, hospitalar e condições de trabalho, é evidente que as ideias da teoria de risco do autor se aplica intensamente nos grupos sociais mais vulneráveis à exposição e contaminação à COVID-19. Estes grupos são, em sua maioria, moradores de periferias e favelas, que já são expostos a diversos riscos e vulnerabilidades desde sua constituição e a negação da cidade a estes.

Segundo Carlos (2020), a cidade expõe a vulnerabilidade e segregação ao mesmo tempo, em que reforça a desigualdade social nestes espaços, pois, nestas áreas, há sujeitos que moram em casas pequenas, onde nas torneiras nem sempre sai água, em muitos casos com banheiros compartilhados, com fogões desligados e mesas sem comida. Um ponto a ser destacado sobre as periferias e favelas em tempos de COVID-19 é a fragilidade do discurso das orientações sanitárias nestes locais.

Para a maioria das populações que habitam estes espaços, o isolamento social é uma tarefa quase impossível, pois, geralmente, vivem em locais superpovoados e, principalmente, ocupam postos de trabalhos subalternos. Isso, quando estão em uma situação mais estável de emprego formal, pois há ainda uma grande parte desta população que trabalha em empregos mais precários, temporários ou até mesmo informais. Essa realidade, coloca a necessidade da sobrevivência em voga, pois é nas ruas da cidade que estes corpos garantem sua possibilidade de sobreviver. Dessa forma, para essa população

ISSN: 2236-837X 
que trabalha nas ruas, com atividades que condicionam sua sobrevivência, fazer isolamento social se torna uma impossibilidade.

Se as condições de trabalho das populações das periferias suscitam estes sujeitos à riscos e, consequentemente, vulnerabilidade, a estrutura domiciliar e a moradia, também são agravantes a essa situação. Tal realidade está diretamente relacionada às dificuldades econômicas, que estão na constituição das periferias e favelas, espaços mais afastados e com menos amenidades, geralmente às margens da metrópole, por conta da especulação imobiliária. As condições de precariedade estrutural em relação à moradia é diferente nas diversas periferias e favelas do Brasil, porém, o descaso da ação do Estado para com as populações que habitam estes locais faz parecer impossível uma tarefa simples, que é manter-se higienizado.

Essas desigualdades sociais que expõem, ainda mais, grupos vulnerabilizados à riscos, não parecem fazer diferença para parte da população brasileira que é contrária às medidas de isolamento social, que veem seu discurso sendo legitimado pelo, até então, presidente da república, Jair Messias Bolsonaro. O presidente, em diversas de suas falas públicas, evoca e elucida práticas que podem colaborar para o aumento da situação de risco que várias dessas populações, e seus seguidores vivenciam. No dia em que o Brasil ultrapassou o número de mortes da China, epicentro inicial da doença, o presidente respondeu a uma repórter: "E daí? Quer que eu faça o quê?" quando perguntado sobre o fato.

Nesse dia em questão, além de ter ultrapassado o número de mortos da China, o Brasil havia batido recorde de mortes diárias notificadas pela COVID-19. Naquele período, as medidas de distanciamento de 1 metro entre todas as pessoas e o uso de máscaras já eram divulgadas como medidas preventivas eficazes, contudo, Jair Bolsonaro e sua equipe foram registrados sem o uso de máscaras e com uma proximidade evidente entre todos.

Essas práticas corroboram com a lógica de que alguns corpos valem mais que outros. Isso pode ser observado também em outro pronunciamento do presidente da República em que sugere a normatização da perda de algumas vidas, pois é aceitável para não parar a economia. A partir destas falas, podemos concluir que na concepção do presidente, algumas vidas são descartáveis em relação a outras.

A partir dessa prática, fica evidenciada a banalização do perigo e das medidas protetivas, que pode ser replicada por seus seguidores, por pensar que é uma prática segura. Na contramão do recomendado pela Organização Mundial da Saúde (OMS) e nas medidas adotadas por vários líderes mundiais que, apesar das dificuldades, estão acompanhando seus países durante a pandemia, o presidente brasileiro decidiu não

ISSN: 2236-837X 
incentivar e adotar as medidas de proteção, distanciamento e isolamento social. O que estamos vendo, é a gestão do caos como estratégia.

Utilizando-se do discurso irracional da preocupação com a economia, o presidente da República demonstra quase nenhuma preocupação com a saúde de sua população, principalmente daquela porção mais vulnerável residente das periferias e favelas do Brasil. Dito de outra forma, o discurso de Jair Bolsonaro endossa que, para que a economia continue funcionando, pessoas em situação de vulnerabilidade pelas condições de vida às quais foram submetidas seriam expostas ao risco de contaminação pelo vírus.

Além de implantar dúvidas em parte da população, geralmente seus apoiadores, acerca da gravidade da situação pandêmica em que vivemos, o presidente tira a atenção do combate à dispersão do novo Coronavírus para a incompetência político-administrativa dos seus ministérios. Suas infelizes e absurdas declarações em cadeia nacional, potencializam a confiança no risco.

Segundo Castro et al. (2005), a não percepção e lucidez na identificação de possíveis riscos, ou até mesmo a aceitação de um nível de risco calculado, são garantidos pela confiança.

"Se a confiança pressupõe não conhecer processos e procedimentos de sistemas e se estes, no que lhe concerne, têm alguma probabilidade de falharem em seus procedimentos de segurança, a sociedade (ou parte dela) está vulnerável aos riscos derivados de falhas nos sistemas em questão". (CASTRO et al., 2005 p. 19)

Não há ações específicas para as populações periféricas que se encontram em uma situação de vulnerabilidade agravada. As ações que tangem os grupos subalternizados nas cidades, nos campos e nas aldeias deveriam ser integradas junto às organizações não governamentais e lideranças de comunidades que já atuam ativamente nas periferias e favelas, lutando contra a dispersão da COVID-19.

Os corpos periféricos, que já viviam um genocídio cotidiano pela polícia e milícia, agora são cirurgicamente abandonados à sombra do capital (VOLOCHKO, 2020). Verificase que o capital constitui-se como um instrumento de superação ou diminuição de riscos nas mais diversas instâncias em que estes se instituem, seja para subsidiar o diagnóstico, financiar medidas preventivas ou, ainda, em casos nos quais o capital pode solucionar, em certa medida, algumas das perdas proporcionadas pelas catástrofes. No caso da superação da pandemia corrente, o impacto não é diferente - o urbano concentra riquezas mas também concentra pobrezas e onde a pobreza está concentrada, há uma concentração, também, da letalidade e do contágio do vírus.

ISSN: 2236-837X 
Em teoria, todos os corpos são atingidos da mesma maneira pelo referido vírus, mas muito se fala sobre a pandemia não ser exatamente democrática. A distinção social do vírus funda-se nas capacidades de diminuição dos riscos de contágio, por exemplo, na possibilidade de isolamento social pelas classes médias e se estende até a falta de adequação sanitária e hospitalar. $O$ direito à cidade e aos encontros se inverte: a aversão a aglomerações para as classes mais altas ao lado da obrigação da circulação e aglomerações para os mais pobres que dependem do trabalho e dividem habitações pequenas e aglomeradas (SIMONI, 2020).

A cidade, ela mesma, deveria ser um comum, pois ela é uma obra coletiva. Contudo, o comum urbano e as práticas de comunalidade são capitalizadas e apropriadas na metrópole. $\mathrm{O}$ fim do direito à cidade é marcado, cada vez mais, pelo direito ao consumo na cidade (LIMA, 2019). Os comuns nas metrópoles brasileiras encontram-se incorporados nas favelas e ocupações urbanas, pois os sujeitos que ocupam esses espaços fazem-se valer de estratégias de sobrevivência e informalidade que permitem que sobrevivam na urbe. Entretanto, são as práticas comunais e a divisão de espaços que mais colocam essas populações em risco no tempo presente: o isolamento é possibilitado pelo cercamento, e o não deslocamento na cidade só se faz possível para quem acumula capital - nas periferias não é essa a realidade.

Ao observarmos o fato de que proximidade, vizinhança e convívio não raramente são noções veiculadas ao modo de vida urbano. Ancoradas no neoliberalismo, ondas de cercamentos de terras promovem a possibilidade de loteamentos maiores às classes mais ricas, enquanto as classes populares encontram-se em situação de rua ou em favelas e grandes adensamentos populacionais.

Quando falamos na cidade como um direito, estamos falando de uma não exclusão da sociedade urbana e do acesso a qualidades, benefícios e equipamentos da vida urbana. Porém, não se pode analisar este contexto sem considerar a divisão a este direito - ou a falta dele - aos corpos pertencentes às classes populares. Há uma ausência de participação na formação da cidade por estes grupos que foram excluídos do desenvolvimento econômico e acesso aos bens sociais mais básicos. De acordo com Harvey (2012), o direito à cidade é o direito de mudar a nós mesmos pela mudança da cidade.

\section{A COVID-19 em Belo Horizonte: Destaque para a periferia}

Belo Horizonte foi pensada e planejada privilegiando a distribuição e fluxo da população na destinação de seus serviços. Porém, assim como diversas outras cidades do Brasil, se mostra incapaz de acolher toda sua população e garantir o acesso e direito à

ISSN: 2236-837X 
cidade, principalmente aos corpos periféricos. Segundo Harvey (2012), basta olhar para a história e ver que as cidades foram dirigidas pelo capital mais do que pelas populações.

A capital mineira não disponibilizava um espaço para acomodação dos trabalhadores que estavam diretamente relacionados à sua construção, e suas famílias. Estes grupos tiveram que ocupar espaços à margem da cidade. Nos anos seguintes à construção da capital mineira, estes espaços, que foram extremamente expostos a fortes desigualdades, com habitações precárias, alta densidade populacional, além de precárias infraestruturas sanitária e urbana, constituíram as atuais periferias e favelas de Belo Horizonte. Este contexto é inerente à velha questão da urbanização brasileira.

A expansão urbana das grandes cidades do Brasil, assim como das médias e pequenas cidades, potencializaram a produção de desigualdades sociais nestes territórios. Segundo Lefebvre (2001), a burguesia, com seu projeto de cidade ideal, fragilizou toda a vida urbana. O urbanismo foi considerado como instrumento principal utilizado por classe para modificar o espaço urbano, e considerava uma espécie de patologia espacial no incontrolável desejo de espaço urbano harmonioso e normalizante, ou seja, sem as periferias e favelas. A população residente destes territórios se vê obrigada a criar estratégias de sobrevivência sem o papel do Estado, comprometendo, assim, sua cidadania.

De acordo com Dagnino (2004), em um contexto neoliberal a noção da cidadania toma outro significado. Um dos principais elementos que constituem essa nova concepção de cidadania, diz respeito à redefinição da ideia de direitos. Sendo assim, é o direito a ter direitos. Essa concepção não se limita a legitimação do Estado ao acesso a direitos previamente estabelecidos, ela inclui a elaboração de novos direitos, que surgem da não passividade dos sujeitos e suas lutas. "O direito à autonomia sobre o próprio corpo, o direito à proteção do meio ambiente, o direito à moradia, são exemplos (intencionalmente muito diferentes) dessa criação de direitos novos" (DAGNINO, 2004. p. 104)

Se os territórios das periferias e favelas das metrópoles brasileiras, assim como os corpos que os ocupam, são considerados as fontes dos problemas urbanos, uma metrópole ideal seria aquela que não abriga estes territórios. Essa afirmação está diretamente relacionada ao projeto de cidade desenhado pela burguesia e identifica nas populações periféricas os problemas inerentes à própria constituição da cidade neoliberal. Este discurso tem o claro objetivo de distinção entre os grupos sociais. Trata-se de uma divisão simbólica, que hierarquiza os corpos segundo sua ocupação no espaço.

Apesar de estarem localizadas no território da capital mineira, diversas periferias e favelas belo-horizontinas tem seu acesso a bens e serviços sociais negado às suas populações, assim como não também foi negado o direito à cidade. A luta travada por estas

ISSN: 2236-837X 
populações dentro do espaço urbano é uma realidade inquestionável e de difícil solução. Essa luta envolve muito mais do que o acesso e direito a uma porção de terra na metrópole, são outros bens essenciais à sobrevivência a serem apropriados, além do direito de pertencer e participar efetivamente da cidade oficial, como cidadãos.

A partir da análise dos dados disponibilizados pela Prefeitura de Belo Horizonte (PBH) ao longo do ano de 2020, através do Boletim Epidemiológico semanal, foram construídos dois mapas que representam os casos de infecções (Mapa 1) e óbitos (Mapa 2) causados pela COVID-19 em regionais e bairros da capital mineira. Esses dados foram justapostos ao Índice de Vulnerabilidade de Saúde (IVS), também disponibilizado pela PBH. Os dados de infecção e óbitos pelo vírus na escala dos bairros e regionais de Belo Horizonte são referentes aos meses de junho e julho de 2020. Já os dados do IVS são referentes ao ano de 2012.

A partir da análise, há um certo padrão no que diz respeito à contaminação e óbitos por COVID-19 em Belo Horizonte. Como pode-se observar na figura 1, o número de contaminações/infecções pelo vírus é maior nos bairros de classe média, localizados na região centro-sul como, por exemplo: Belvedere, Buritis, Gutierrez, Floresta, Funcionários e Lourdes. Porém, esses números não se convertem em óbitos, como pode-se observar na figura 2. Os bairros periféricos e favelas de Belo Horizonte têm o maior número de óbitos, mesmo sem ter o maior número de contaminações. Isso pode ser observado nos bairros Santa Cruz, Alto Vera Cruz, Cabana do Pai Tomás, Coqueiros e Lindéia, que são periferias e/ou favelas no município.

ISSN: 2236-837X 


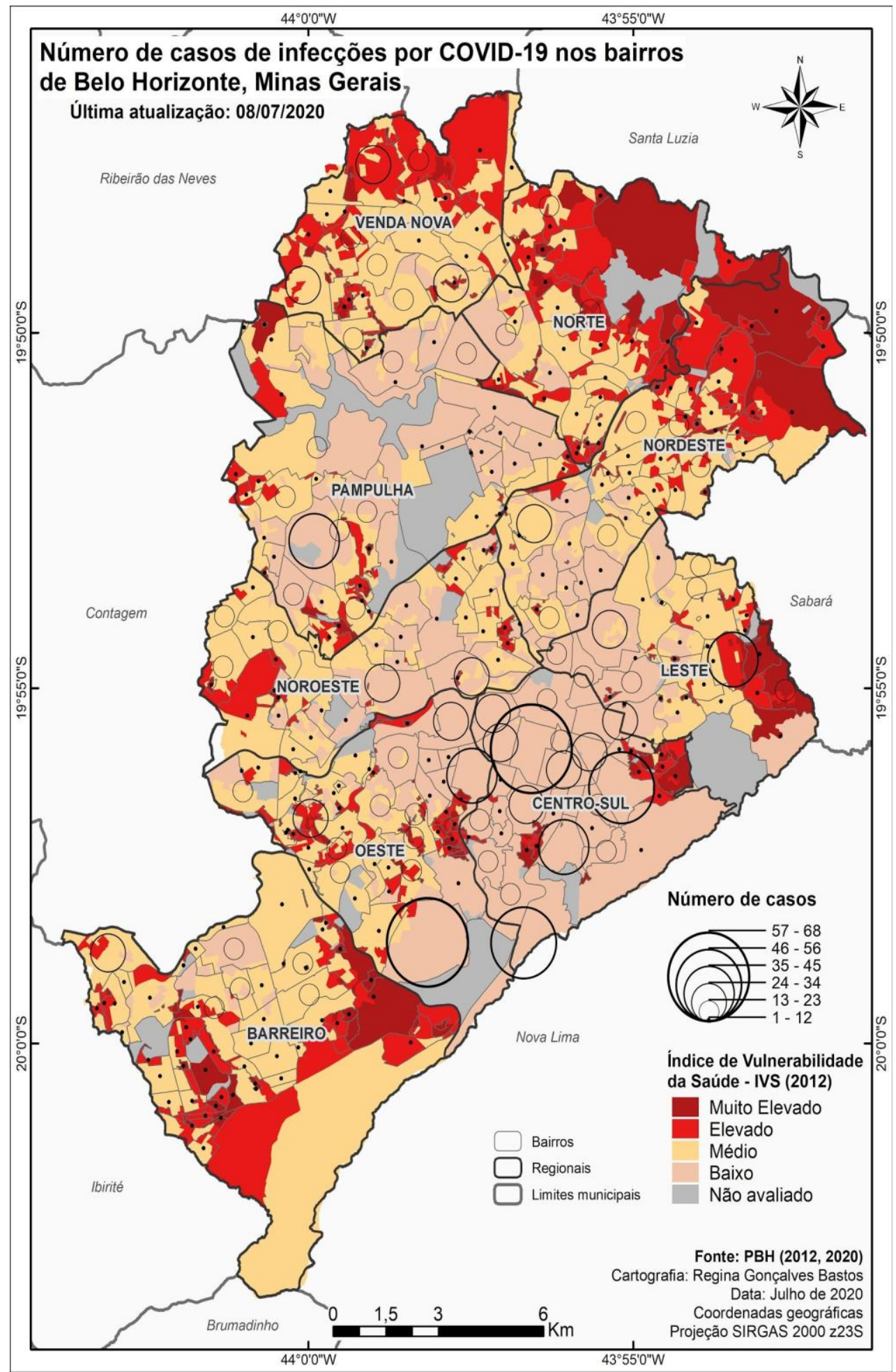

Figura 1. Contaminação por COVID19 em Belo Horizonte. Fonte: PBH. Elaboração: Regina Bastos, 2020.

ISSN: 2236-837X 


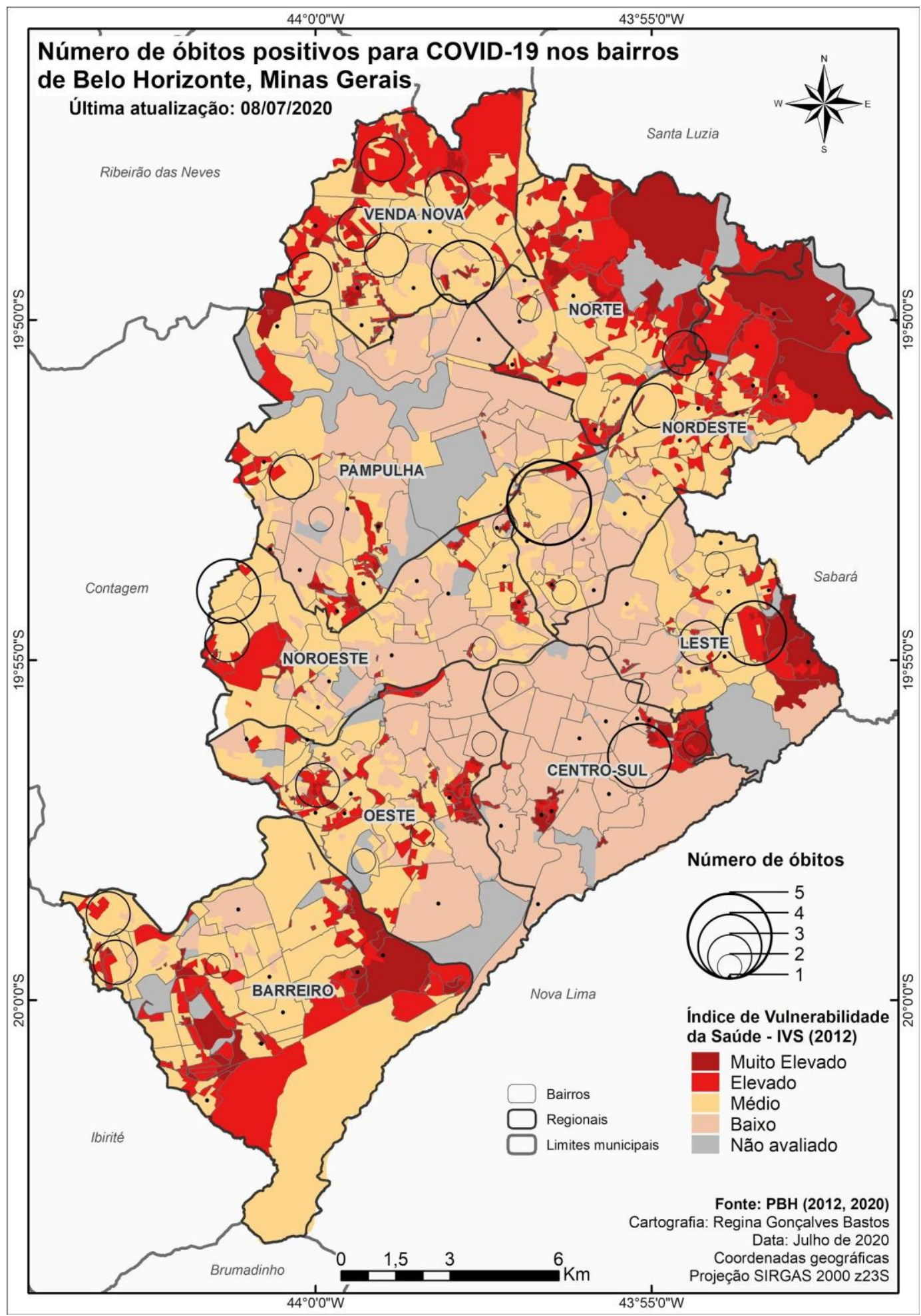

Figura 2. Óbitos por COVID19 em Belo Horizonte. Fonte: PBH. Elaboração: Regina Bastos, 2020.

ISSN: 2236-837X

REVISTA 
Desde sua fundação, Belo Horizonte é marcada por ocupações irregulares e profundas desigualdades sociais - não apenas a capital mineira, mas as cidades que passaram pelo processo de urbanização no Brasil são marcadas por crescentes exclusões e impossibilidades de acumulação de capital a partir de sujeitos subalternizados. Grupos da classe trabalhadora ocupam espaços à margem fisicamente e nas prioridades da atenção pública. Com habitações e infraestruturas sanitária e urbana precárias, a realidade dos moradores das favelas e periferias de Belo Horizonte sempre foi anormal. Especialmente agora, com a crise da COVID-19, essas populações, que já eram abandonadas à própria sorte e dependiam de suas redes de resistência e sobrevivência, são colocadas frente a uma situação de vulnerabilidade e risco agravada, que não recebe atenção específica do governo.

O risco sempre esteve associado à noção de incerteza e exposição ao perigo, mas agora, em um tempo de crise, a certeza do perigo faz-se cada vez mais real, demonstrada através dos números e estatísticas já dispostas neste trabalho. Contudo, os riscos e perigos da crise presente não afetam todos os lugares da mesma forma. De acordo com Escobar (1996), nenhum problema ou fenômeno ocorre da mesma maneira nos diferentes locais do globo, e essa diferenciação também se dá até mesmo em diferentes territorialidades dentro de municípios, como é o caso observado em Belo Horizonte. Marandola Junior e Hogan (2009) afirmam que diferentes partes da cidade, pulsam em diferentes ritmos e a COVID-19 evidencia essa desigualdade. É possível observar, nos mapas, que a vulnerabilidade social agrava a ocorrência do perigo frente à COVID-19, gerando um número desproporcional de óbitos em locais mais vulneráveis, em comparação com locais menos vulneráveis tendo como base o número de casos de contágio.

\section{Considerações finais}

Podemos apontar como uma das possíveis justificativas para esse panorama em Belo Horizonte, o início da pandemia em seu território. A doença tem seu início nos lugares de maior concentração do capital, por serem áreas mais cosmopolitas e com mais conexões e fluxos internacionais, e por abrigarem a população que "buscou" o vírus no exterior, sendo estes, os primeiros contaminados no país.

Em um momento seguido, o vírus se espalhou pela metrópole através dos trabalhadores, como domésticas e entregadores, em seus deslocamentos. A distinção social do vírus funda-se nas capacidades de diminuição dos riscos de contágio, por

ISSN: 2236-837X

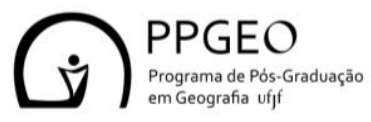


exemplo, na possibilidade de isolamento social pelas classes médias e se estende até a falta de adequação sanitária.

As implicações adotadas pelos governos estaduais e municipais do Brasil diante da dispersão da COVID-19, não se mostram, significativamente, eficazes da mesma forma em todos os lugares e para todos os corpos. As condições sociais precárias, inerentes ao capitalismo globalizado e a sociedade neoliberal, expõe de forma intensa como a falta de acesso à infraestrutura básica, bens e serviços sociais, como a saúde, impacta de forma ainda mais intensa e negativa às populações que vivem em condições mais precárias e vulneráveis.

Nas metrópoles brasileiras não há intermitências tênues entre os corpos menos e mais vulneráveis. A desigualdade social cria um abismo quase definitivo entre estes corpos. Essas diferenças expostas pela pandemia demarcam a possibilidade do cuidado e de acesso, já que tanto as possibilidades de isolamento social quanto a garantia de acesso a serviços de saúde e de assistência são distribuídos de forma desigual entre as classes e as camadas sociais. Um exemplo disso é a superlotação dos hospitais e a falta de leitos nas Unidades de Terapia Intensiva (UTIs) às quais são expostas as populações vulneráveis.

A pandemia do novo Coronavírus descortina, ao menos no caso das metrópoles, a dimensão desigual deste espaço. De acordo com PORTO (2020), é a atual crise, relacionada a um conjunto de crises que são anteriores a COVID-19, mas que são radicalizadas pela pandemia. Os corpos que já enfrentam as desigualdades sociais que caracterizam o Brasil, durante a pandemia, se deparam com estas desigualdades mais potencializadas.

No caso de Belo Horizonte, os bairros das classes mais altas são os bairros que agrupam o maior caso de contaminações. A partir disso, seria esperado que o maior número de mortes também fosse concentrado nesses mesmos territórios. Contudo, o que ocorre, é um aprofundamento das vulnerabilidades e riscos que já se estabeleciam em territórios historicamente marginalizados e vulnerabilizados: o maior número de óbitos pela COVID-19 concentra-se nos bairros mais pobres da cidade.

\section{Agradecimentos}

O presente trabalho foi realizado com apoio da Coordenação de Aperfeiçoamento de Pessoal de Nível Superior - Brasil (CAPES) - Código de Financiamento 001.

\section{Referências}

BECK, U. Sociedade de risco: Rumo a uma outra modernidade. 2. Ed. São Paulo: Editora 34, 2011.

ISSN: 2236-837X

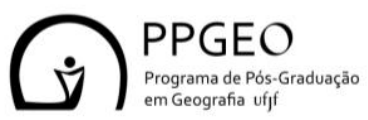


BRUNDTLAND (1987). Report. of the World Commission on Environment and Development: Our Common Future. United Nations General Assembly document A/42/427.

CARLOS, A. F. A. COVID-19 e a crise urbana. -- São Paulo : FFLCH/USP, 2020.

CASTRO, C. M; PEIXOTO, M. N. O; RIO, G. A. P. Riscos Ambientais e Geografia: Conceituações, Abordagens e Escalas. Anuário do Instituto de Geociências - UFRJ. Vol. 28-2 / 2005 p. $11-30$

DAGNINO, E. Sociedade civil e espaços públicos no Brasil. São Paulo: Paz e Terra, 2002.

DARDOT, P; LAVAL, C. Commun. Paris: La Découverte, 2015.

DINIZ, S. C; SILVA, G. L; GUERCI, M. R. G. "Economia Popular Urbana e o Covid-19: desafios e propostas para a Região Metropolitana de Belo Horizonte," Notas Técnicas Cedeplar-UFMG 008, Cedeplar, Universidade Federal de Minas Gerais.

ESCOBAR, A. Constructing nature: elements for a poststructural ecology. In: PEET, R. WATTS, M. (eds.). Liberation ecologies: Environment, development, social movements. London; New York: Routledge, 1996. p. 46-68.

GALTON, F. Hereditary Genius: An Inquiry Into Its Laws and Consequences. New and rev. ed., with an American preface. New York: Appleton, 1883.

GONÇALVES, C. W. P. Formação sócio espacial e questão ambiental no Brasil. In: BECKER, B. et al. (orgs). Geografia e meio ambiente no Brasil. Rio de Janeiro: Hucitec/UGI, 1995. p. 309-333.

HARVEY, D. O direito à cidade. Revista Piauí, edição 82, 2012.

LEFEBVRE, H. O direito à cidade. Tradução Rubens Eduardo Frias. São Paulo: Centauro, 2001. Título original: Le Droit à la Ville. ISBN 978-85-88208-97-1.

LIMA, C. M. S. As transformações dos usos do espaço público [manuscrito] : a rua Sapucaí em Belo Horizonte (MG) Trabalho de Conclusão de Curso (graduação) - Universidade Federal de Minas Gerais, Instituto de Geociências, 2019

MARANDOLA JUNIOR, E; HOGAN, D. J. Vulnerabilidade do lugar vs. vulnerabilidade sociodemográfica: implicações metodológicas de uma velha questão. Revista Brasileira de Estudos Populacionais, Rio de Janeiro, v. 26, n. 2, p.161-181, jul. 2009.

MBEMBE, A. "Necropolitics". Public Culture, 15(1): 11-40. 2003.

MBEMBE, A. CRítICA DA RAZÃo NEGRA. Ed. Antígona, Lisboa, 2017.

MENDONÇA, F. Riscos, vulnerabilidades e resiliência socioambientais urbanas: inovações na análise geográfica. Revista da ANPEGE. v. 7, n. 1 p. 111-118. out. 2011.

MONTE-MÓR, R. L. Urbanização extensiva e lógicas de povoamento: um olhar ambiental. In: SANTOS, M.; SOUZA, M. A. A.; SILVEIRA, M.L. (orgs.). Território: globalização e fragmentação. São Paulo: Hucitec, ANPUR, 1994.

MOTTA, L. G. Análise Crítica da Narrativa. Brasília: Editora Universidade de Brasília, 2013

MORADO, D., 2020. Vista do lavar as mãos contra o Coronavírus: mas, e a água? | APS EM REVISTA. [online] Apsemrevista.org. Available at: <https://apsemrevista.org/aps/article/view/61/51> Acesso em 28 de Abril de 2020.

PORTO, M. F. No meio da crise civilizatória tem uma pandemia: desvelando vulnerabilidade e potencialidades emancipatórias. Revista visa em debate. Fundação Fiocruz, 2020.

ISSN: 2236-837X 
PREFEITURA DE BELO HORIZONTE. Boletim epidemiológico e assistencial COVID-19. Disponível em: <shorturl.at/gnuzW> Acesso em Julho de 2020.

SACHS, W. The rise and decline of an ideal.Wupperdalpapers, No. 108, 2000

SIMONI, C. A COVID-19 e o direito à cidade dos pobres no Brasil. in COVID-19 e a crise urbana [recurso eletrônico] / Coordenadora: Ana Fani Alessandri Carlos. -- São Paulo : FFLCH/USP, 2020.

TONUCCI, F. J; COSTA, H. O comum e a metrópole brasileira: além do impasse da reforma urbana? In: XVII Encontro Nacional da ANPUR, 2017, São Paulo. Anais. Desenvolvimento, crise e resistência: quais os caminhos do planejamento urbano e regional? São Paulo: FAUUSP, 2017.

UNICEF. Tudo O Que Você Precisa Saber Sobre Como Lavar As Mãos Para Se Proteger Contra o Coronavírus. [online] Disponível em: <https://www.unicef.org/brazil/historias/tudo-o-que-voceprecisa-saber-sobre-como-lavar-maos-para-se-proteger-contra-o-coronavirus $>$ Acesso em 28 de Abril de 2020

VALENCIO, N. Quem tem medo da remoção? A violência institucional contra moradores de "áreas de risco". In:34.o Encontro Anual da ANPOCS, 2010, Caxambu. Anais.... Caxambu: ANPOCS, 2010. p. 1-22.

VOLOCHKO, D. O COTIDIANO DOS POBRES NÃO PODE PARAR: A PANDEMIA E A NECRODEMOGRAFIA DO CAPITAL. in COVID-19 e a crise urbana / Coordenadora: Ana Fani Alessandri Carlos. -- São Paulo: FFLCH/USP, 2020. 